\title{
The pulsed nature of the nightside contribution to polar cap convection: repetitive substorm activity under steady interplanetary driving
}

\author{
P. E. Sandholt ${ }^{1}$, Y. L. Andalsvik ${ }^{1}$, and C. J. Farrugia ${ }^{2}$ \\ ${ }^{1}$ Department of Physics, University of Oslo, Oslo, Norway \\ ${ }^{2}$ Space Science Center, University of New Hampshire, Durham, USA \\ Correspondence to: P. E. Sandholt (p.e.sandholt@fys.uio.no)
}

Received: 30 March 2012 - Revised: 14 August 2012 - Accepted: 15 September 2012 - Published: 12 October 2012

\begin{abstract}
The aim of this study is to investigate the relative contributions of dayside and nightside processes to the spatial and temporal structure of polar cap plasma convection. The central parameter is the cross-polar cap potential (CPCP). Selecting a 10-h-long interval of stable interplanetary driving by an interplanetary CME (ICME), we are able to distinguish between the dayside and nightside sources of the convection. The event was initiated by an abrupt enhancement of the magnetopause (MP) reconnection rate triggered by a southward turning of the ICME magnetic field. This was followed by a long interval $(10 \mathrm{~h})$ of steady and strong driving. Under the latter condition a long series of electrojet intensifications was observed which recurred at $50 \mathrm{~min}$ intervals. The detailed temporal structure of polar cap convection in relation to polar cap contraction events is obtained by combining continuous ground observations of convection-related magnetic deflections (including polar cap magnetic indices in the Northern and Southern Hemispheres, PCN and PCS) and the more direct, but lower-resolution ion drift data obtained from a satellite (DMSP F13) in polar orbit. The observed PCN enhancements combined with DMSP satellite observations (F13 and F15 data) of polar cap contractions during the evolution of selected substorm expansions allowed us to estimate the CPCP enhancements (25\%) associated with individual events in the series. Ground-satellite conjunctions are further used to investigate the spatial structure of polar cap convection, i.e., the homogeneous plasma flow in the centre $\left(V_{\mathrm{i}} \leq 1 \mathrm{~km} \mathrm{~s}^{-1}\right)$ versus channels of enhanced antisunward flows $\left(V_{\mathrm{i}} \geq 1 \mathrm{~km} \mathrm{~s}^{-1}\right)$ along the periphery of the polar cap. We emphasise the temporal structure of these polar cap flow
\end{abstract}

phenomena in relation to the prevailing solar wind forcing and the repetitive substorm activity.

Keywords. Ionosphere (Plasma convection) - Magnetospheric physics (Polar cap phenomena; Solar windmagnetosphere interactions)

\section{Introduction}

The two-source nature of polar cap convection is a basic feature of the expansion-contraction model of magnetospheric plasma convection (Siscoe and Huang, 1985; Lockwood et al., 1990; Cowley and Lockwood, 1992). The relative contributions to the cross-polar cap potential (CPCP) from the dayside (CPCP/day) and nightside ( $\mathrm{CPCP} /$ night) sources during intervals of substorm activity have been studied in recent years, applying different observational techniques (Bristow et al., 2004; Lockwood et al., 2009; Kullen et al., 2010; Gordeev et al., 2011; Andalsvik et al., 2011, 2012).

Fox et al. (1999), Grocott et al. (2002) and Provan et al. (2004) estimated the convection response to isolated substorms by continuous observations, applying a ground-based radar technique. Grocott et al. (2010) studied the convection responses in the dayside and nightside sectors of the polar cap to substorms occurring during intervals of positive and negative interplanetary magnetic field (IMF) $B_{\mathrm{y}}$ polarity, applying a superposed epoch analysis.

Bristow et al. (2004) documented CPCP fluctuations of $20 \mathrm{kV}$ amplitude, as obtained from DMSP satellite ion drift measurements during intervals of steady interplanetary conditions. In the MHD simulation study of Gordeev et al. 
(2011) substorm onsets gave rise to rapid, moderate $(25 \%)$ CPCP increases in intervals of steady southward-directed IMF. Lockwood et al. (2009) reported a statistical study of CPCP variability in the context of substorm phases. They found that the nightside contribution (CPCP/night) is larger than the dayside source (CPCP/day) in all substorm phases except for the growth phase.

A documentation of polar cap convection in the context of (i) repetitive substorms and (ii) the detailed substructure of substorm evolution, from the pre-breakup arc through breakup and poleward expansion, poleward boundary intensifications (PBIs) and auroral streamers, is lacking at present. A relevant approach to shed light on these issues by direct observations is to select intervals of clearly defined substorms occurring during conditions of quasi-steady solar wind forcing, as measured by the geoeffective interplanetary electric field ( $E_{\mathrm{KL}}$; see Kan and Lee, 1979). ( $E_{\mathrm{KL}}$ is defined as $\left.V B_{\mathrm{T}} \sin ^{2}(\theta / 2)\right)$ where $B_{\mathrm{T}}=\left(B_{\mathrm{y}}^{2}+B_{\mathrm{z}}^{2}\right)^{1 / 2}$ in GSM coordinates and $\theta$ is the IMF clock angle.) Quasisteady driving can be observed during Earth passage of interplanetary CMEs (ICMEs), an approach that was first suggested by Farrugia et al. (1993). One can then take advantage of the well-organised behaviour of the magnetic fields in ICMEs (Burlaga et al., 1981; Andalsvik et al., 2012). An increase of the CPCP of about $33 \%$ (from 120 to $160 \mathrm{kV}$ ) during the evolution of a substorm, under extremely steady interplanetary CME conditions, was observed by Andalsvik et al. (2012).

The polar cap (PC) index is a measure of equivalent ionospheric convection in the center of the polar cap which is considered to be linearly related to $E_{\mathrm{KL}}$ (Troshichev et al., 2000). The general, statistical response of the PC index (in both winter and summer hemispheres) to substorm activity, as measured by the AE/AL-index, has been studied by Janzhura et al. (2007), Kullen et al. (2010) and Gao et al. (2012). In the detailed case study of Kullen et al. (2009) 10 (mostly weak substorms) tail dipolarisations is compared with $\mathrm{AE}$ index, $\mathrm{PC}$ indices and solar wind parameters. It shows that clear correlations between $\mathrm{AE}$ and $\mathrm{PC}$ index exist only for substorms with peak AE clearly above $200 \mathrm{nT}$. Janzhura et al. (2007) found that in the growth phase of substorms the PC index in summer polar cap rises faster and reaches a higher value than in the winter hemisphere. In expansion phase development of substorms the response is strongest in the winter hemisphere. The winter PC index always reflects better the ALevents, independent on whether the winter PC index is measured in the same hemisphere or not. This is a most relevant background for our case study of repetitive substorm activity where we aim at distinguishing between the dayside and nightside sources of the PC index (summer and winter hemispheres) and the CPCP. In this context we also refer to the results of Kullen et al. (2010) who were able to separate the dayside and nightside contributions to the CPCP (CPCP/day and CPCP/night), (see their Fig. 7). We shall get back to these earlier results when discussing our main findings.
A critical point in such studies is to monitor the temporal evolution of polar cap convection and the CPCP with high temporal resolution. The two currently available techniques of direct CPCP measurements, i.e., via satellite ion drift data (Hairston et al., 1998) and ground-based radars (Greenwald et al., 1999; Grocott et al., 2002; Provan et al., 2004), are both incomplete. This is due to the limited temporal resolution of the satellite measurements, on one hand, and the missing spatial coverage at high latitudes of the present radars, on the other. In this study, we shall, therefore, use the polar cap index obtained for the Northern (summer) and Southern (winter) Hemispheres (PCN and PCS) as a proxy for antisunward convection in the near-pole region (Troshichev et al., 2000). For a sub-interval of four hours, including four major ALexcursions, we combine the DMSP F13 ion drift data from the three best polar cap passes, i.e., successive passes that all reach high latitudes, and the $\mathrm{PCN}$-index, in order to to derive a detailed temporal evolution of the CPCP. The result is compared with the Hill-Siscoe formula for the CPCP which is applicable to the prevailing high level of solar wind forcing (see Eq. 1 in Hairston et al., 2003).

Another aim of this study is to follow the detailed evolution of one substorm using very good ground-satellite conjunctions in the dusk to pre-midnight sector. In this approach we apply the combination of passes by satellites DMSP F13 and F15, occurring in different stages of the evolution of this particular substorm. Latitudinal profiles of precipitation, ion drift, and Birkeland currents were obtained in the 18:0020:00 MLT sector. This information is combined with the evolution of auroral electrojet activity inferred from ground magnetograms. Here we shall take advantage of the wide latitudinal coverage of the ground magnetometer chain (IMAGE) in Svalbard - Scandinavia - Finland (Tomita et al., 2011) in the monitoring of the geomagnetic activity from the polar cap across the auroral oval to mid-latitudes as these stations moved from noon to dusk under similar interplanetary conditions. We shall, thereby, be able to investigate the evolution of the PC indices in the context of the following three latitude regimes of geomagnetic deflection: (i) polar cap convection bays, (ii) westward electrojet (WEJ) deflections (ALindex), and (iii) mid-latitude convection bays.

This dataset allows us to study the detailed evolution of plasma convection in the central polar cap as substorm activity progresses from pre-breakup via the expansion phase, with its series of PBIs and streamers, through recovery (see e.g., Sandholt et al., 2002). From the known association between PBIs/streamers, bursty bulk flows (BBFs) and transient magnetotail reconnection (see e.g., Sergeev et al., 2004; Shi et al., 2012, and Lyons et al., 2012) the expected effect on polar cap convection from such reconnection events can be investigated on the basis of ground data alone. An initial observation of this kind of relationship between substorm evolution and polar cap convection has been recently reported by Andalsvik et al. (2012). Here we follow up with a more detailed analysis of an interval of ICME passage at Earth, 
characterised by a long-lasting $(10 \mathrm{~h})$, southwest-directed $\left(B_{\mathrm{Z}}<0 ; B_{\mathrm{y}}<0\right)$ magnetic field of large amplitude (15 to $17 \mathrm{nT}$ ), with the IMF clock angle (polar angle in GSM Y-Z plane) varying around an average value of $\sim 145^{\circ}$, with corresponding moderate $E_{\mathrm{KL}}$ variations within $5.5-7 \mathrm{mV} \mathrm{m}^{-1}$, on 30 May 2005. In this interval a series of electrojet intensifications (AL-excursions to between -1000 and $-2000 \mathrm{nT}$ ), recurring at $40-120 \mathrm{~min}$ intervals, were superimposed on a continuously high disturbance level ( $\mathrm{AL} \leq-500 \mathrm{nT})$. From these data we infer that the repetitive substorms gave rise to a pulsed mode of polar cap convection. The pulsing reflects the episodic contribution from the repetitive sequence of substorms.

Concerning the second aspect of our study, i.e., the spatial structure of polar cap convection appearing in the form of flow channels (convection jets) at the boundary of the polar cap in the night sector, these flows are considered to be preferentially a winter phenomenon and associated with conductivity gradients at the polar cap boundary during intervals of high solar wind forcing, as measured by $E_{\mathrm{KL}}$ (Wang et al., 2010). Their results are confirmed by the present case study. We observed a strong flow channel with the flow speed reaching $2 \mathrm{~km} \mathrm{~s}^{-1}$ at the polar cap boundary in the Southern (winter) Hemisphere $\left(-74^{\circ} \mathrm{MLAT} / 20 \mathrm{MLT}\right)$. We point out that this flow event is observed at the time of $\mathrm{PBI} /$ streamer activity in the same MLT sector in the Northern (summer) Hemisphere. This is an interesting observation which is consistent with the ideas and observations of Andalsvik et al. (2011, 2012), but the relationship between these polar cap flow channel events and substorm activity (substorm onset, PBIs, streamers, and BBFs) is still uncertain and needs further documentation (see e.g., Lyons et al., 2012).

\section{Data description}

\subsection{Wind interplanetary data}

Figure 1 shows interplanetary (IP) data from spacecraft Wind during passage of an ICME on 30 May 2005. The ICME extends from 01:00-23:00 UT (Richardson and Cane, 2010). Features of the ICME are (i) strong magnetic fields, (ii) high $\alpha$ particle-to-proton number density ratios, and a low proton $\beta$. In the middle of the interval we study (12:00 UT) Wind was located at $(225.4,99.8,8.0) R_{\mathrm{E}}$ (GSE coordinates). A clear directional discontinuity (DD) occur at 05:45 UT, when the $\boldsymbol{B}$-field changed orientation from being $B_{\mathrm{y}}$-dominated to $B_{\mathrm{Z}}$-dominated. This type of DD is often referred to as a southward turning. It is associated with a sharp increase in the $\alpha / \mathrm{p}$ density ratio. At this time the geoeffective IP $\boldsymbol{E}$-field, $E_{\mathrm{KL}}$, increased sharply from 4 to $7 \mathrm{mV} \mathrm{m}^{-1}$ (see bottom panel). The new south-west orientation is exceptionally stable during the 10-h long interval from 05:40-15:40 UT when $E_{\mathrm{KL}}$ stays between $5.5-7 \mathrm{mV} \mathrm{m}^{-1}$. The clock angle of the $\boldsymbol{B}$-field in the GSM Y-Z plane fluctuates between $135-165^{\circ}$.

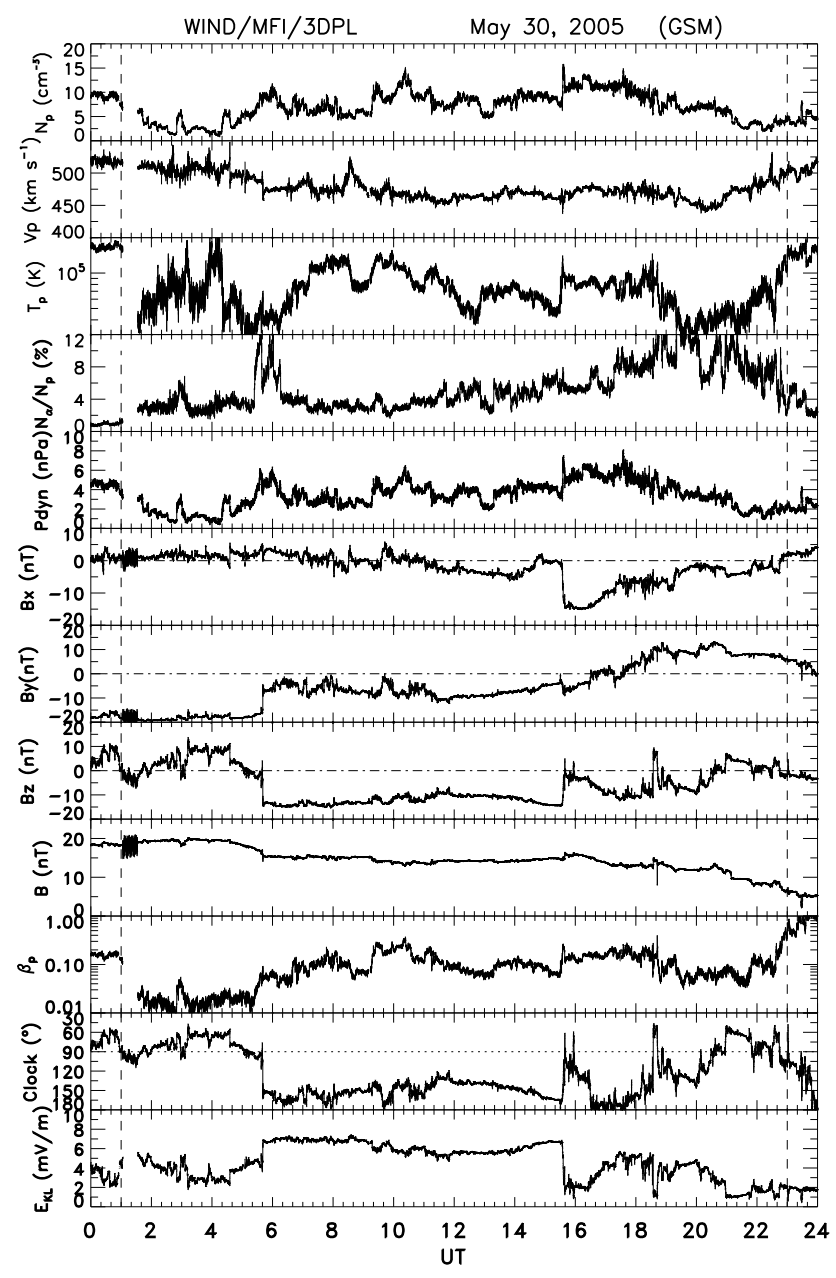

Fig. 1. Interplanetary data from spacecraft Wind on 30 May 2005. Panels from top to bottom shows proton density, bulk speed, proton temperature, alpha/proton number density ratio, dynamic pressure, magnetic field components $B_{\mathrm{X}}, B_{\mathrm{y}}$, and $B_{\mathrm{z}}$ (GSM coordinates), the total field, plasma beta, clock angle of the $\boldsymbol{B}$-field, and the reconnection electric field $E_{\mathrm{KL}}$. The ICME interval from 01:00 to 23:00 UT is delimited by the vertical dashed guidelines.

Among the other relevant IP parameters of this ICME we mention: (i) proton density between $5-10 \mathrm{~cm}^{-3}$, (ii) bulk speed around $475 \mathrm{~km} \mathrm{~s}^{-1}$, (iii) dynamic pressure between 2$6 \mathrm{nPa}$, (iv) strong magnetic field (15-20 nT), and (v) low proton beta $\left(\beta_{\mathrm{p}}\right)$.

We shall study the magnetosphere-ionosphere response to (i) the initial southward turning and (ii) the long interval of steady and strong forcing of the magnetosphere following this southward turning, with emphasis on temporalspatial structure of polar cap convection in relation to substorm activity. The interval selected is particularly interesting for our purpose of investigating the relative contributions of the dayside and nightside magnetospheric sources of spatial-temporal structure of polar cap convection. The dayside source as measured by geoeffective interplanetary 
electric field, $E_{\mathrm{KL}}$, increased rapidly at 06:40 UT, taking into account the DD propagation delay $(60 \mathrm{~min})$ from Wind to Earth, and then stayed at a relatively constant level (5.5$7 \mathrm{mV} \mathrm{m}^{-1}$ ) for $10 \mathrm{~h}$. In such a case, it is easy to separate the dayside (magnetopause reconnection) and nightside (magnetotail reconnection) sources of polar cap convection. The level of interplanetary driving from 06:40 UT onwards is at such a high value $\left(5.5-7 \mathrm{mV} \mathrm{m}^{-1}\right)$ that its contribution to dayside magnetic flux erosion and the cross-polar cap potential (CPCP) is expected to approach a level of saturation (Siscoe et al., 2002; Muhlbachler et al., 2005) after the initial phase of R1 field-aligned current build-up (see Siscoe et al., 2011). The magnetosphere-ionosphere response to the enhanced level of magnetopause reconnection rate, with emphasis on ground magnetic deflections in the cusp region and polar cap convection in the near-pole region, as measured by the PC-indices, is a central topic of this study.

\subsection{Observation geometry}

Figure 2 shows a schematic illustration of the observation geometry with emphasis on the substorm interval 14:4015:25 UT, which includes passes of spacecraft DMSP F15 (pre-midnight to pre-noon) and F13 (dusk-to-dawn) during the intervals 14:37-14:58 and 15:09-15:24, respectively. The track of spacecraft F15 from pre-noon to pre-midnight in the Southern Hemisphere during the interval 15:32-15:53 UT is marked by the blue dashed arrowed line.

Based on the combined ground-satellite data we have drawn an approximate pattern of large-scale convection (streamlines) as well as electrojet currents and precipitation features observed along the satellite tracks: (i) auroral oval crossing marked by double-arrowed lines, (ii) ion isotropy boundary (arrows), (iii) westward electrojets (WEJ; red) and associated outward-directed FACs in two phases (14:42 and 15:13 UT) of the substorm, (iv) polar cap boundary/boundary intensification (PBI; 15:13 UT)), and (v) flow channel at the polar cap boundary in the south (marked FC 3; blue).

The convection state indicated in the figure was initiated by the rapid southward turning of the ICME magnetic field affecting the Earth's magnetosphere from 06:40 UT onwards. We shall follow the ground magnetic responses to the indicated convection features, as well as the substorm electrojet currents, within the MLAT range $57-75^{\circ}$, as the ground stations in Svalbard - Scandinavia - Finland moved with the Earth from $\sim 10: 00$ to 19:00 MLT within the interval 06:4016:30 UT, during the continuous, strong and stable forcing of the magnetosphere by the presence of the large amplitude, south-west directed magnetic field of the ICME.

We selected the interval 14:40-16:10 UT for a detailed study of substorm evolution since (i) this interval is representative for the long interval of repetitive substorms (07:0020:00 UT), and (ii) in this interval we have a very good coverage of ground-satellite data in the different substorm phases. Recall that we want to study the evolution of polar cap con-

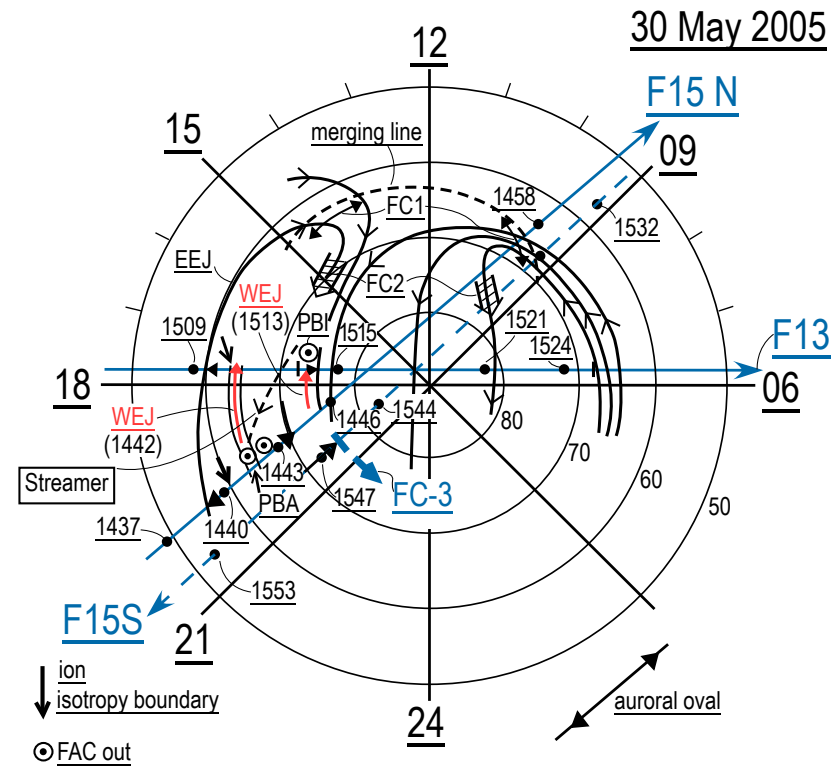

Fig. 2. Illustration of observation geometry on 30 May 2005 with schematic convection pattern and flow channels along the polar cap boundary superimposed. Three satellite passes occurring during different phases of substorm evolution are marked: (i) DMSP F15 (pre-midnight to pre-noon) and DMSP F13 (dusk to dawn) during the intervals 14:37-14:58 and 15:09-15:24 UT, respectively, in the Northern Hemisphere and (ii) one F15 pass in the south (blue dashed line) from pre-noon to pre-midnight during the interval 15:32-15:53 UT. Approximate convection pattern (streamlines) and merging line (dashed curved line) are shown as well as eastward (EEJ) and westward (WEJ; 14:42 and 15:13 UT; red arrows) electrojets and precipitation features at dusk/pre-midnight (isotropy boundary, pre-breakup arc (PBA; 14:43 UT), poleward boundary intensification (PBI; 15:13 UT) observed along the satellite tracks in the north and south (see text for details). FC 3 marks a nightside flow channel $\left(V_{\mathrm{i}}>2 \mathrm{~km} \mathrm{~s}^{-1}\right)$ at the the polar cap boundary in the south traversed by spacecraft F15 just before 15:47 UT (see data below). Flow channels along the polar cap boundary on the dayside are marked FC 1 (newly open field lines) and FC 2 (old open field lines). The coordinate system is MLAT versus MLT.

vection (CPCP) in relation to the different substorm phases and substructures (PBIs/streamers).

The three satellite passes marked in the figure occurred in different stages of substorm evolution in this interval (14:40-16:10 UT): (i) F15 crossed the evening sector oval in the pre-breakup phase (14:40-14:44 UT) and flow channel FC 1 (14:57 UT) at 10:00 MLT; (ii) F13 crossed the oval at dusk with a poleward boundary arc in the expansion phase (15:09-15:15 UT), and polar cap during 15:1515:25 UT; and (iii) F15 crossed a flow channel at the polar cap boundary in the pre-midnight sector of the Southern Hemisphere (blue arrow marked FC 3; 15:46 UT) during the late expansion phase.

We remark that flow channels FC 1 and FC 2 represent flows in different stages of the evolution of open field lines 
in the Dungey (1961) convection cycle. FC 1 is located on newly open field lines and is accompanied by poleward moving auroral forms (PMAFs) appearing on either side of noon, as documented during winter conditions (Sandholt and Farrugia, 2007). FC 2 is a few $100 \mathrm{~km}$ wide channel of enhanced $\left(>1 \mathrm{~km} \mathrm{~s}^{-1}\right)$ antisunward convection on old open field lines (embedded in polar rain precipitation) along the periphery of the dayside polar cap. This represents the flow excited during an intermediate interval occurring approximately from 10-20 min after magnetopause reconnection, when the open field lines are connected to the solar wind, before these field lines sink into the tail lobes. The fastest flows in this channel are expected to be associated with the large conductivity gradient appearing at the polar cap boundary in the winter hemisphere (Sandholt and Farrugia, 2009). The spatial structure (the $\boldsymbol{E}$-field gradient) in these flows is expected to be less prominent in the summer hemisphere, but the temporal structure, attributed to flux transfer event (FTE) flux tubes moving along the periphery of the polar cap, as first predicted by Southwood (1987), is still prominent even during the summer conditions.

\subsection{Ground magnetometer data}

Figure 3 shows the geoeffective interplanetary electric field $\left(E_{\mathrm{KL}}\right.$ ), the geomagnetic indices PCN (north; summer), PCS (south; winter) and the AL-index. $E_{\mathrm{KL}}$ is based on the Wind data given in Fig. 1. Here we added $1 \mathrm{~h}$ to the Wind measurements in order to take into account the Wind-to-Earth propagation delay.

The PC-index (in both hemispheres) is a measure of equivalent convection in the near-pole region (Troshichev et al., 2000). It is derived from ground magnetic deflection due to the ionospheric Hall-current associated with plasma convection. Because of the two-source nature of polar cap convection the PC-index is shown to be linearly related to $E_{\mathrm{KL}}$ and the AL-index (Gao et al., 2012). It is expressed in the unit of $\mathrm{mV} \mathrm{m}^{-1}$.

We note the following features: (i) abrupt increase of $E_{\mathrm{KL}}$ from $4-7 \mathrm{mV} \mathrm{m}^{-1}$ at 06:40 UT, associated with southward turning of the ICME magnetic field; (ii) stable, high level of $E_{\mathrm{KL}}\left(5-7 \mathrm{mV} \mathrm{m}^{-1}\right)$ during the subsequent $10 \mathrm{~h}$; (iii) initial phase of increasing PC-index from 06:40-07:10 UT; (iv) a series of PCN/PCS enhancements during the interval 07:1020:00 UT; and (v) a long series of negative AL-excursions (westward electrojet enhancements) during the same interval (07:10-20:00 UT).

The two sources of the PC-index, i.e., $E_{\mathrm{KL}}$ and the $\mathrm{AL}$ index, (see Gao et al., 2012), are clearly manifest in this case, i.e., the initial response to the $E_{\mathrm{KL}}$ enhancement and the response to the repetitive substorm activity (AL-excursions). The sensitivity to the AL-excursions is observed to be highest in the PCS (winter)-index. A particularly high sensitivity of PCS to AL-events (PCS/night) is observed from 14:40 UT onwards (PCS reaching $\sim 15 \mathrm{mV} \mathrm{m}^{-1}$ ). This seasonal depen-
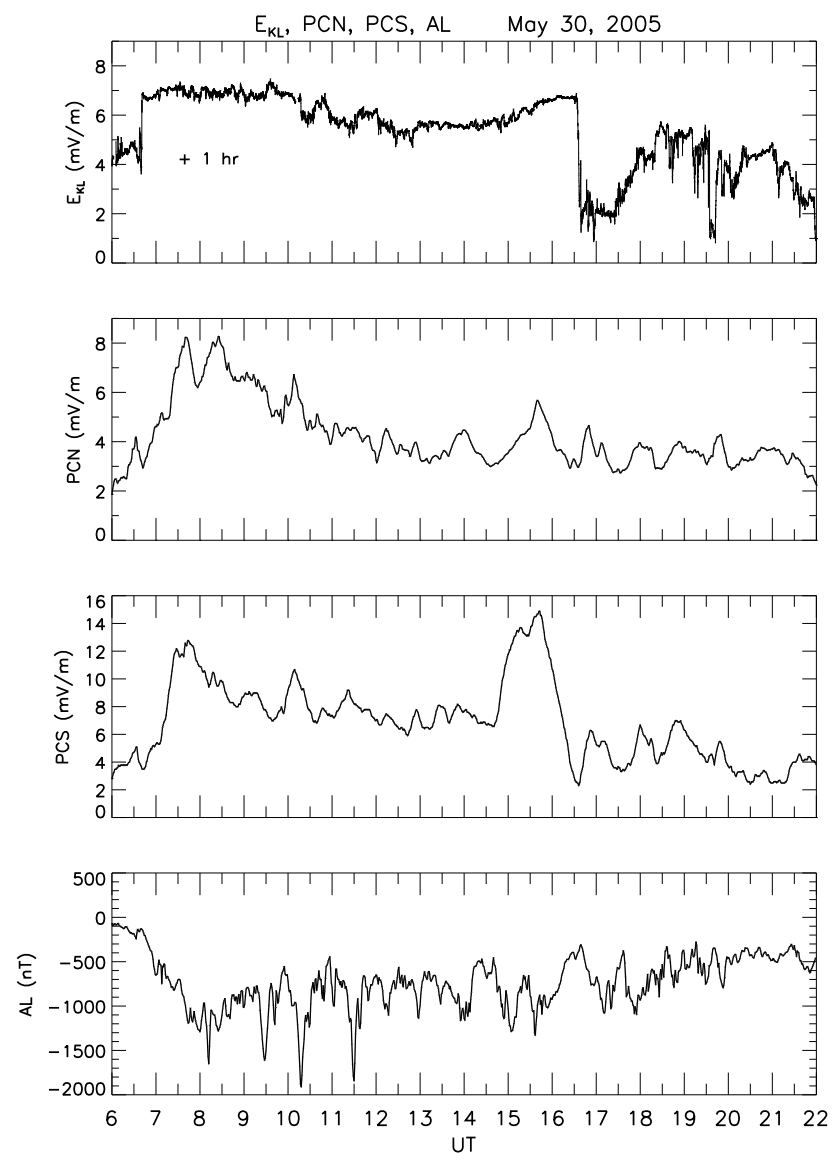

Fig. 3. Panels from top to bottom shows $E_{\mathrm{KL}}$ based on observations from spacecraft Wind, the polar cap indices in the Northern (PCN) and Southern (PCS) Hemispheres, and the AL-index (bottom panel) for the interval 06:00-22:00 UT (30 May 2005).

dence of the AL-response is in good agreement with previous work (Janzhura et al., 2007).

Since the dayside source of polar cap convection, as measured by $E_{\mathrm{KL}}$, is relatively constant after the southward turning, this case is particularly suitable for separating the dayside and nightside sources of polar cap convection. We start by distinguishing between the dayside and nightside sources of the PC index, which we shall refer to as PC/day and $\mathrm{PC} /$ night, respectively. $\mathrm{PC} /$ night is the component which is related to substorm activity, as measured by the AL-index. The PC/day component may be inferred from the background (inter-substorm) trend that is obtained by subtracting the short-lived, AL-related enhancements in the PC-index traces.

Based on the above reasoning on the two sources of the PC-index and the observed PCN trace we may infer from Fig. 3 a three-stage evolution of the PCN-index: (i) an initial transient phase of $\mathrm{PC}$ enhancement with contributions from both dayside (polar cap expansion phase) and nightside sources, (ii) an intermediate phase with decreasing PCN/day component, and (iii) a long interval of relatively constant 


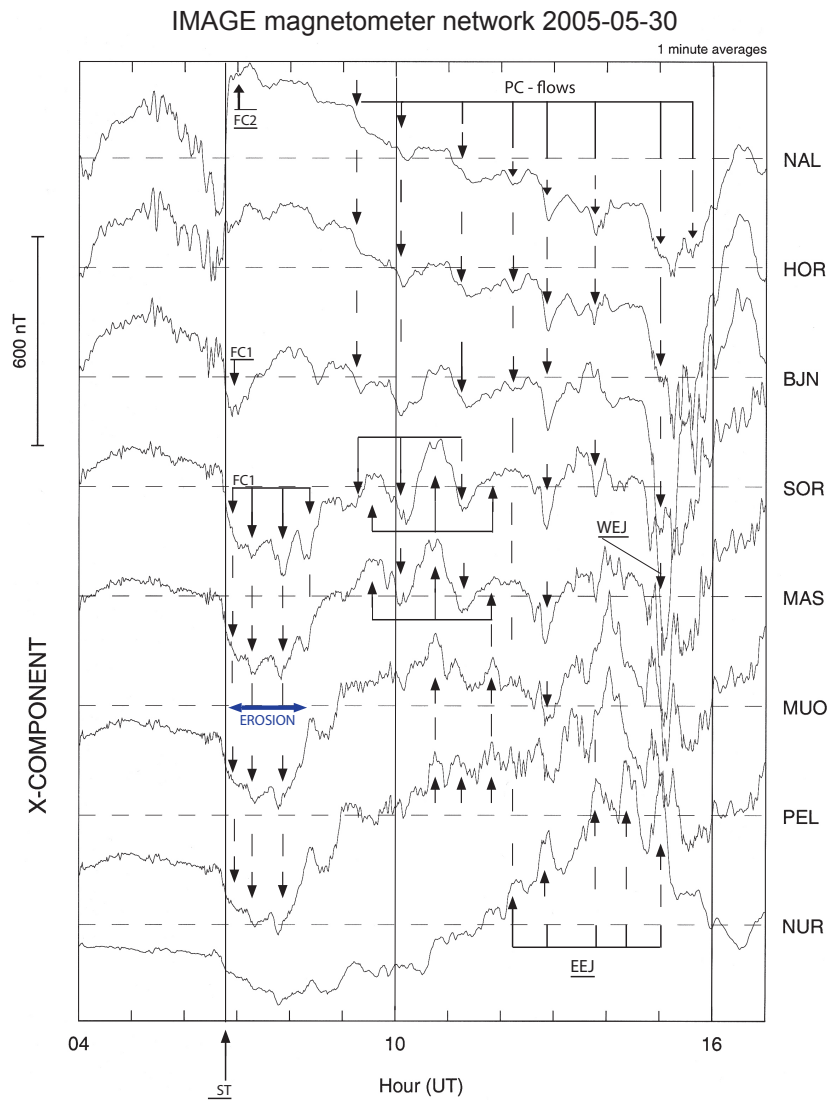

Fig. 4. X-component magnetic deflections from ground stations in Svalbard - Scandinavia - Finland during the interval 04:0017:00 UT (30 May 2005), ordered by decreasing latitude: NAL (75.2 ${ }^{\circ}$ MLAT), HOR (74.1 ${ }^{\circ}$ MLAT), BJN (71.4 MLAT), SOR (67.3 ${ }^{\circ}$ MLAT), MAS (66. $2^{\circ}$ MLAT), MUO (64.7 $7^{\circ}$ MLAT), PEL $\left(63.6^{\circ}\right.$ MLAT), and NUR (56.9 $9^{\circ}$ MLAT). Magnetic effects related to specific flow features and electrojet currents have been marked. See text for details.

$\mathrm{PCN} /$ day (=3) with a series of PCN/night events (recurring at 50 min intervals) superimposed from 12:00 UT onwards.

Figure 4 shows $\mathrm{X}$-component magnetic deflections from ground stations in Svalbard - Scandinavia - Finland during the interval 04:00-17:00 UT. We shall point out the following magnetic deflection features, corresponding to different spatial (MLT/MLAT) plasma flow regimes: (i) FC 2 flows in the prenoon polar cap (06:40-08:20 UT/71-75 MLAT), (ii) FC 1 flows at lower latitudes in the cusp region (06:4008:20 UT/64-67 ${ }^{\circ} \mathrm{MLAT}$ ), (iii) flows associated with polar cap boundary motions (ground stations being alternatively in positive and negative $\mathrm{X}$-component regimes) in postnoon sector (09:00-12:00 UT; 66-67 MLAT), (iv) substormrelated polar cap flow events (09:00-15:00 UT), and (v) electrojet events in the postnoon-dusk sector from 12:00 UT onwards (polar cap - auroral oval (WEJ) - mid-latitudes (EEJ)).

From the measurements shown in Fig. 4, we may distinguish between magnetic deflection events associated with the dayside magnetopause source of plasma convection (events in the interval 06:40-08:20 UT marked FC 1/FC 2), and events relating to the nightside (magnetotail) source. From the top and bottom panels we infer that the IMAGE chain of stations are increasingly sensitive to the nightside source during the interval 09:00-15:00 UT. The three major AL-deflections in the interval 09:00-12:00 UT (Fig. 3) are well correlated with the oscillating negative/positive Xcomponent deflections appearing in the SOR-MAS (66$67^{\circ}$ MLAT) traces in the same interval. This behaviour is indicative of PC boundary motions in the close vicinity of these stations.

The magnetic deflections in the interval 06:40-08:20 UT represent the response to the rapid southward turning of the ICME magnetic field recorded by spacecraft Wind at 05:45 UT whose arrival at Earth is shown by the first vertical guideline. This response consists of (i) large negative $\mathrm{X}$-deflections with the centre expanding equatorward in the MLAT range from $71-65^{\circ}$ MLAT (BJN-MUO) and (ii) positive $\mathrm{X}$-deflections expanding equatorward from NAL to BJN (75-71 $1^{\circ}$ MLAT). These magnetic effects at $\sim 10: 00$ MLT can be explained by the establishment of a convection pattern as shown in Fig. 2 and the corresponding ionospheric Hall currents.

Feature (i) is related to the noonward flow marked FC 1, while the positive $\mathrm{X}$-deflection at NAL $\left(75^{\circ} \mathrm{MLAT}\right)$ is related to the antisunward convection near this latitude, marked FC 2 (prenoon) in the NAL magnetogram. From these magnetograms we infer that the convection reversal between the FC 1 and FC 2 flows descended in latitude from that of NAL $\left(75^{\circ} \mathrm{MLAT}\right)$ to that of BJN $\left(71^{\circ} \mathrm{MLAT}\right)$ during the interval 06:40-07:20 UT. From 07:20 to 08:20 UT station $\mathrm{BJN}$ is sensitive to the FC 2 (prenoon) flow regime. After 08:20 UT BJN is increasingly sensitive to FC 3 (substormrelated) events. This is seen in the series of negative $\mathrm{X}$ deflections during the interval 08:20-15:00 UT, as marked in Fig. 4. From the present data, we may infer that the centre of the FC 1/prenoon flows expanded equatorward from $\sim 71^{\circ}$ MLAT (station BJN) to $\sim 65^{\circ}$ MLAT (MAS-MUO) in response to the southward turning.

The observed change in the deflection pattern from 06:40 UT onwards reflects the erosion event and associated polar cap expansion triggered by the rapid southward turning of the ICME magnetic field as it reached Earth. Just before 06:40 UT the polar cap is in a relatively contracted state. This convection state, corresponding to $B_{\mathrm{y}}$-dominant ICME magnetic field (clock angle of approx. $90^{\circ}$ ), probably consists of a composite pattern of merging and lobe cells (see e.g., Crooker et al., 1998). The lobe cell is expected to disappear on arrival of the southward turning.

The interval 06:40-08:20 UT is characterised by strong Hall currents (FC 1 flows) maximising at stations MASMUO. The corresponding X-component negative bay (centred at $\sim 65^{\circ}$ MLAT, as observed in the 10:00-11:30 MLT sector) is marked "EROSION" in Fig. 4. The convection 
pattern shown in the schematic overview figure represents the state of expanded polar cap after the initial erosion event.

Later in the interval of south-west directed ICME magnetic field (09:00 UT onwards), ground deflections associated with the following features (see Fig. 2) can be identified in Fig. 4: (i) mid-latitude positive bays reflecting the eastward electrojet (EEJ) activity from 12:00 UT (15:00 MLT) onwards, (ii) the westward electrojet (WEJ) from 14:40 UT onwards, and (iii) polar cap flow events (see negative convection bays in NAL and HOR magnetograms) from 09:00 UT (12:00 MLT) onwards, with the nightside source (see the ALindex) dominating.

Concerning the spatial distributions of the different regimes of convection and electrojet currents for the present high disturbance level, we also refer to Feldstein et al. (2006) (see their Fig. 15e). We note that our stations become sensitive to the westward electrojet (WEJ) after 14:40 UT. Next we shall, therefore, focus on the evolution of substorm activity appearing at dusk in the interval 14:40-16:10 UT.

Figure 5 shows $\mathrm{X}$-component ground magnetic records from the same stations in Svalbard - Scandinavia - Finland. Here we place focus on the shorter interval 12:00-17:00 UT and we shall emphasise the substorm evolution during the interval 14:40-16:10 UT which contains the following elements: (i) pre-breakup event (pre-breakup arc/PBA identified in satellite data; see below) at the latitudes of MUO-PEL at 14:43 UT, (ii) poleward boundary intensifications (PBIs; see satellite data below) at HOR - BJN - SOR followed by (iii) streamers (blue tilted lines) during the interval 14:5516:10 UT. This substorm activity is placed in the context of polar cap flow events as marked in the top panel. These polar cap flow enhancements are inferred from the PCN index (see Fig. 3).

On the association between auroral streamers (equatorward moving auroral forms emanating from poleward boundary intensifications; PBIs) and their ground magnetic signatures we refer to Sandholt et al. (2002). The phenomenon of auroral streamers is a distinct substructure of the substorm process. It is the auroral signature of bursty bulk flows (BBFs) in the magnetotail (see e.g., Sergeev et al., 2004). In Fig. 5 we document the magnetic signature of auroral streamers and their associated convection channels (streamer channels).

Passages of satellite DMSP F15 across the auroral oval poleward boundary in the pre-midnight sector in the north (pre-breakup phase) and in the Southern Hemisphere during the late expansion phase have been marked at the top of the figure.

\subsection{DMSP F13 and F15 data}

Here we shall report satellite data from two Northern Hemisphere passages and one Southern Hemisphere pass of the auroral oval/polar cap in different stages of substorm evolution.

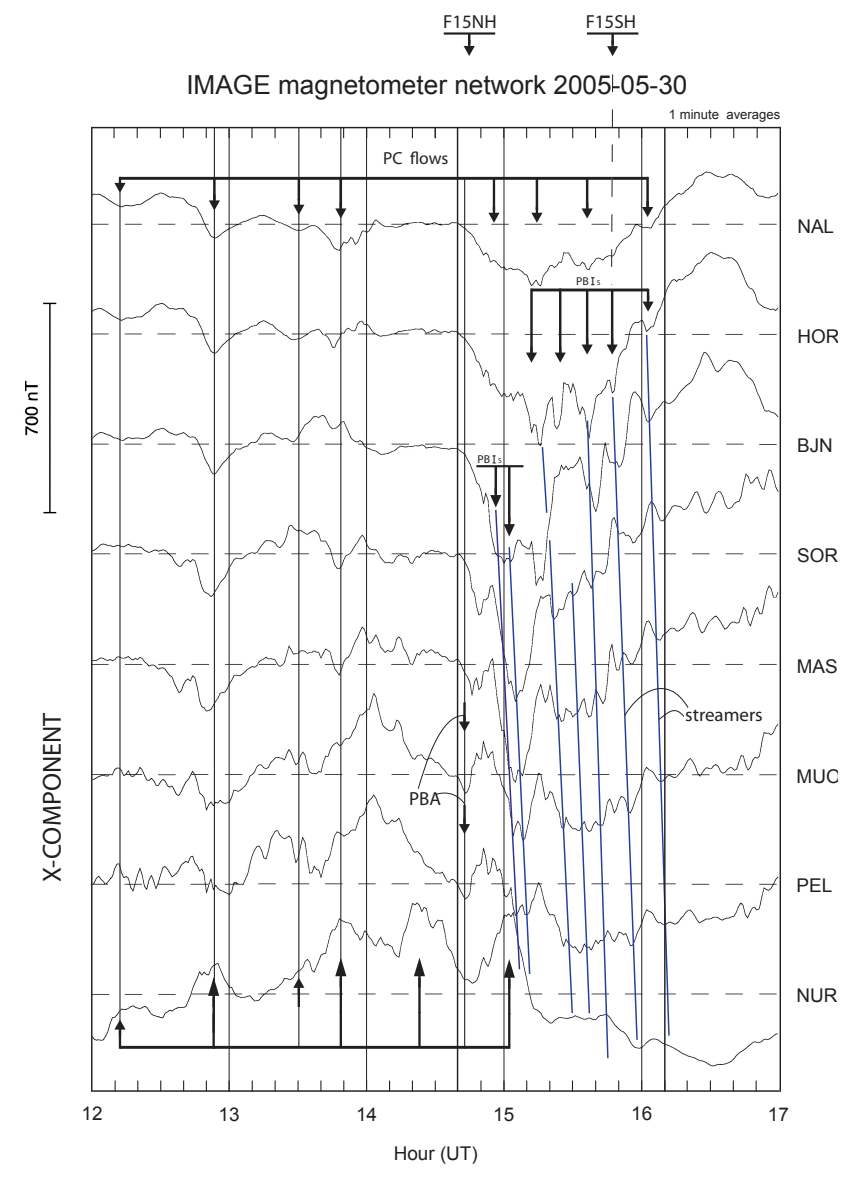

Fig. 5. X-component magnetic deflections from ground stations in Svalbard - Scandinavia - Finland, ordered by decreasing latitude, during the interval 12:00-17:00 UT on 30 May 2005. Various features are marked in the figure: (i) polar cap flow enhancements (upper panel), (ii) poleward boundary intensifications (PBIs) (second and third panels), (iii) auroral streamers (blue tilted lines), (iv) PBA at 14:43 UT and EEJ enhancements (bottom panel). Passes of satellites F15 across the pre-midnight auroral oval in the Northern (NH) and Southern $(\mathrm{SH})$ Hemispheres are marked at the top.

Figure 6 shows DMSP F15 data obtained during the pass from pre-midnight to pre-noon in the interval 14:3415:04 UT. The track is marked in Fig. 2. The crossing of the oval in the pre-midnight sector occurred in the prebreakup phase. We draw attention to the following features: (i) ion isotropy boundary (Newell et al., 1996) identified at $60^{\circ}$ MLAT (equatorward boundary of zone of homogeneous and isotropic ion precipitation; marked by first vertical guideline), (ii) pre-breakup arc (Sergeev et al., 2012) located at $63^{\circ}$ MLAT (14:42 UT), (iii) crossing from oval into the polar cap at $71^{\circ}$ MLAT (14:44 UT), and (iv) flow channel at 67$69^{\circ}$ MLAT/10 MLT.

Feature (ii) is also marked in Fig. 5. The crossing of this arc marks a perfect ground-satellite conjunction (see magnetograms from stations MUO-PEL in Fig. 5). This arc is located at the flow reversal boundary between the eastward 


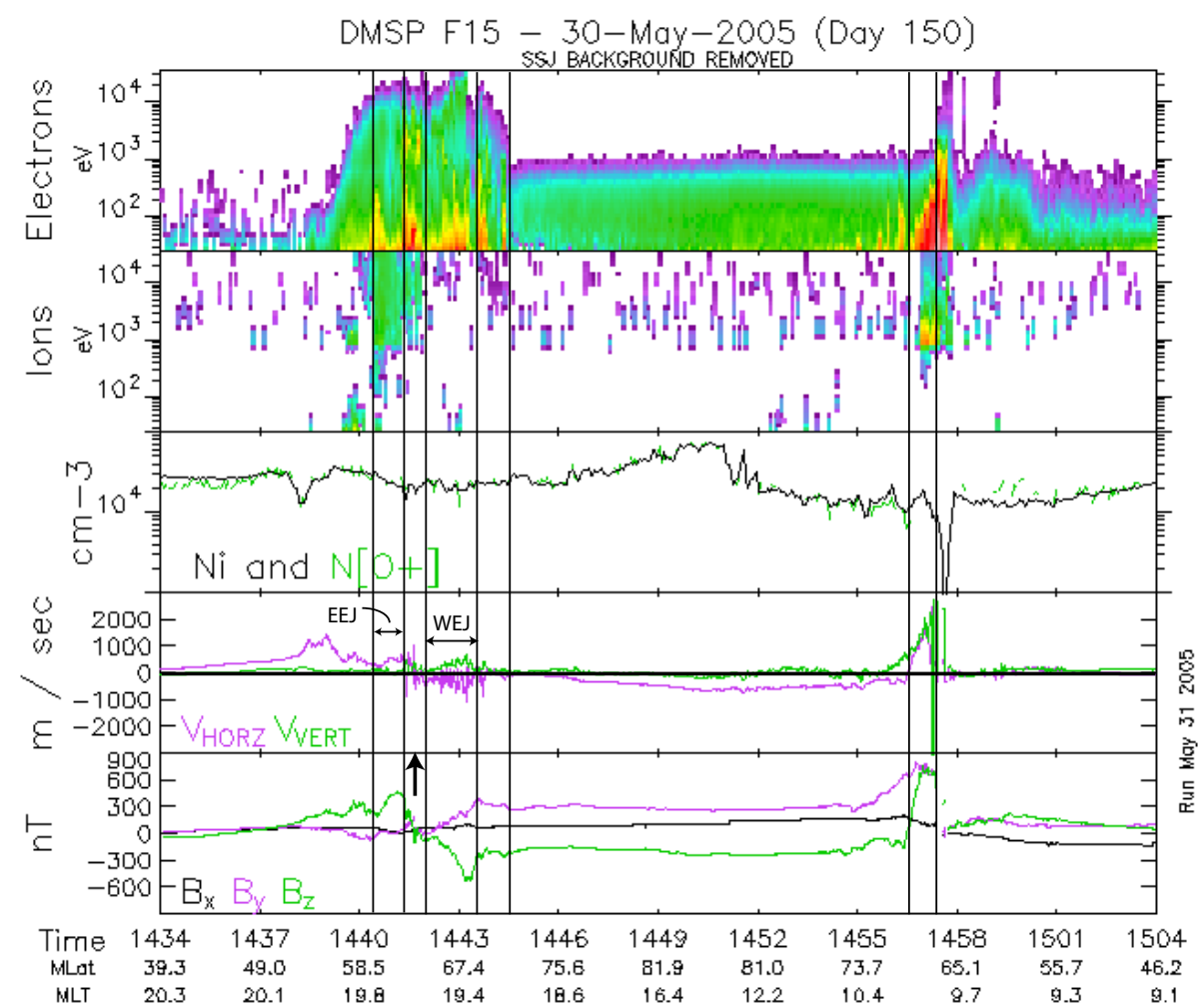

Fig. 6. DMSP F15 data obtained during the pass from pre-midnight to pre-noon in the interval 14:34-15:04 UT. Panels from top to bottom show electron and ion energy spectrograms, ion density, cross-track ion drift (horizontal component in violet), and magnetic deflection components $B_{\mathrm{X}}, B_{\mathrm{y}}$, and $B_{\mathrm{Z}}\left(B_{\mathrm{Z}}\right.$ is the east-west component shown in green). Ion isotropy boundary, pre-breakup arc (PBA), polar cap boundary and flow channel at $67-69^{\circ}$ MLAT/10 MLT are marked by vertical guidelines. Latitude regimes of auroral electrojets (EEJ and WEJ) are indicated.

and westward electrojets. According to Sergeev et al. (2012) the pre-breakup arc maps to a magnetospheric location which is close to the earthward-most edge of the thin cross-tail current sheet. The latter magnetotail location maps to the ion isotropy boundary (Newell et al., 1996).

Immediately after 14:42 UT, the AL-index goes negative (Fig. 3; electrojet enhancement) and the PCN index starts the increase from 3 to 4.3 during the interval 14:43-15:15 UT. The latter is an indication of enhanced antisunward convection (Troshichev et al., 2000).

Figure 7 shows DMSP F13 data obtained during the pass from dusk to dawn in the interval 15:03-15:33 UT. The track is marked in Fig. 2.

We note the following: (i) ion isotropy boundary at $63.8^{\circ}$ MLAT, (ii) poleward boundary arc at $72-74^{\circ}$ MLAT traversed at 15:13 UT (at the time of auroral streamer signatures in the local magnetograms), and (iii) strong homogeneous antisunward convection $\left(1 \mathrm{~km} \mathrm{~s}^{-1}\right)$ across the central polar cap.

The poleward boundary arc $\left(15: 13 \mathrm{UT} ; 72-74^{\circ}\right.$ MLAT $)$ is accompanied by outward-directed Birkeland current as inferred from the negative $B_{\mathrm{Z}}$-gradient in the bottom panel of Fig. 7. The Birkeland current and the westward electrojet as- sociated with this poleward boundary intensification (PBI; see negative $\mathrm{X}$-deflections at stations HOR and $\mathrm{BJN}$ ) have been marked in Fig. 2.

Figure 8 shows F15 data obtained during the Southern Hemisphere pass from pre-noon to pre-midnight in the interval 15:26-15:56 UT. The track is marked in Fig. 2. We notice the presence of an FC 3 flow channel (flow speed approaching $2 \mathrm{~km} \mathrm{~s}^{-1}$ ) at the polar cap boundary traversed at 15:46 UT. This flow channel, which is marked in Fig. 2, occurred during the substorm phase characterised by auroral streamer activity (see Fig. 5).

\subsection{The cross-polar cap potential}

Figure 9 shows successive DMSP F13 tracks in the north and south and cross-track ion drifts for the interval 13:30 18:00 UT. These passes are the most suitable for CPCP estimates on this day since they reach such high latitudes that relevant CPCP values may be derived (see criteria in Hairston et al., 1998). We notice the contrast between the relatively homogeneous antisunward convection at $1 \mathrm{~km} \mathrm{~s}^{-1}$ in the summer hemisphere and the more inhomogeneous flows in the winter hemisphere, characterised by channels of enhanced $\left(1-2 \mathrm{~km} \mathrm{~s}^{-1}\right)$ flows along the periphery of the 


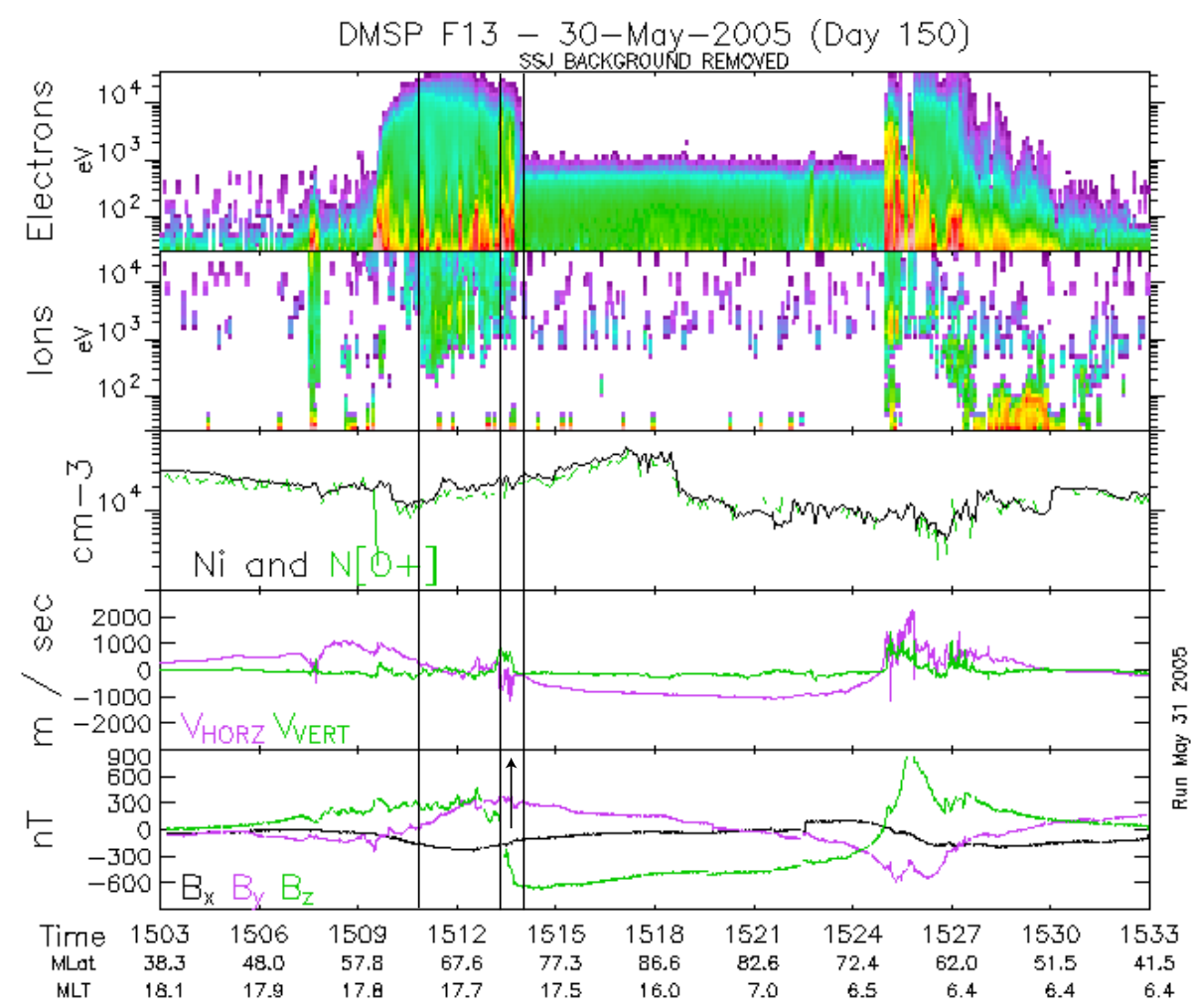

Fig. 7. DMSP F13 data obtained during the pass from dusk to dawn in the interval 15:03-15:33 UT on 30 May 2005. Same format as in Fig. 6.

polar cap. The CPCP values derived for the three $\mathrm{NH}$ passes are: 159 (13:37 UT), 127 (15:18 UT) and $147 \mathrm{kV}(16: 59 \mathrm{UT})$. These values are plotted in the next figure where we shall use the PCN index to interpolate between the three DMSP F13 data points for the purpose of obtaining an estimate of the more detailed temporal variability of the CPCP in this interval.

Figure 10 shows an estimate of the CPCP development during the interval 13:00-17:00 UT. This is based on ion drift data (circled crosses) from the three best Northern Hemisphere passes of satellite DMSP F13 in our interval of study (see Fig. 9). The F13 data points at 13:37, 15:18, and 16:59 UT refer to the centre times of polar cap crossings. PCN index values shown at selected times (dots) illustrate the trend in the variation of the polar cap convection in this interval.

The CPCP estimates in Fig. 10 are based on the following assumptions (approximations): (i) homogeneous polar cap convection (see Fig. 9), (ii) the approximate empirical relationship between CPCP and PCN applicable to the interval from 12:00 UT onwards (persistent phase of solar wind-magnetosphere coupling): $\mathrm{CPCP}(\mathrm{V})=10 \mathrm{PCN}$ $\left(\mathrm{mV} \mathrm{m}^{-1}\right) \times L_{\mathrm{PC}}(\mathrm{km})$, where $L_{\mathrm{PC}}$ is the cross-polar cap distance in the dawn-dusk direction, and (iii) fluctuations of $L_{\mathrm{PC}}$ from $\sim 3000$ to $4000 \mathrm{~km}$ (see Fig. 9).
The observed PCN-fluctuations (3-6 $\mathrm{mV} \mathrm{m}^{-1}$ ) and the estimated CPCP fluctuations $(120-180 \mathrm{kV})$ during the interval 13:00-16:30 UT occurred at the time of relatively steady interplanetary driving, as given by $E_{\mathrm{KL}}$ (slowly increasing from 5.5 to $7 \mathrm{mV} \mathrm{m}^{-1}$ ). We notice that all three CPCP maxima are associated with negative AL-excursions (westward electrojet events). AL-recoveries during the intervals 14:10 14:40 and 15:50-16:40 UT are accompanied by significant PCN (and PCS) decreases.

The $L_{\mathrm{PC}}$ scale on the right-side axis of Fig. 10 gives the $L_{\mathrm{PC}}$ values which corresponds to the CPCP values marked on the left side axis if we apply the empirical relationship given in point (ii) above. The CPCP variability can then be expressed as: $\Delta \mathrm{CPCP} / \mathrm{CPCP}=\Delta \mathrm{PCN} / \mathrm{PCN}+\Delta L_{\mathrm{PC}} / L_{\mathrm{PC}}$, for the prevailing conditions of steady solar wind forcing. According to the expansion-contraction model, PCN and $L_{\mathrm{PC}}$ are expected to vary in counter-phase, i.e., PCN enhancements are accompanied by polar cap contractions. This association is confirmed in our case. The estimated range of CPCP variations in Fig. $10(120-180 \mathrm{kV})$ are consistent with PCN and $L_{\mathrm{PC}}$ variations between $3-6 \mathrm{mV} \mathrm{m}^{-1}$ and 4000 $3200 \mathrm{~km}$, respectively. Related to this we note that the latitudes of the dusk-side polar cap boundary crossings of satellites DMSP F15 and F13 at 14:44 and 15:14 UT correspond to different stages of substorm evolution. The two boundary crossings occurred at $71^{\circ}$ MLAT in the breakup phase (F13 


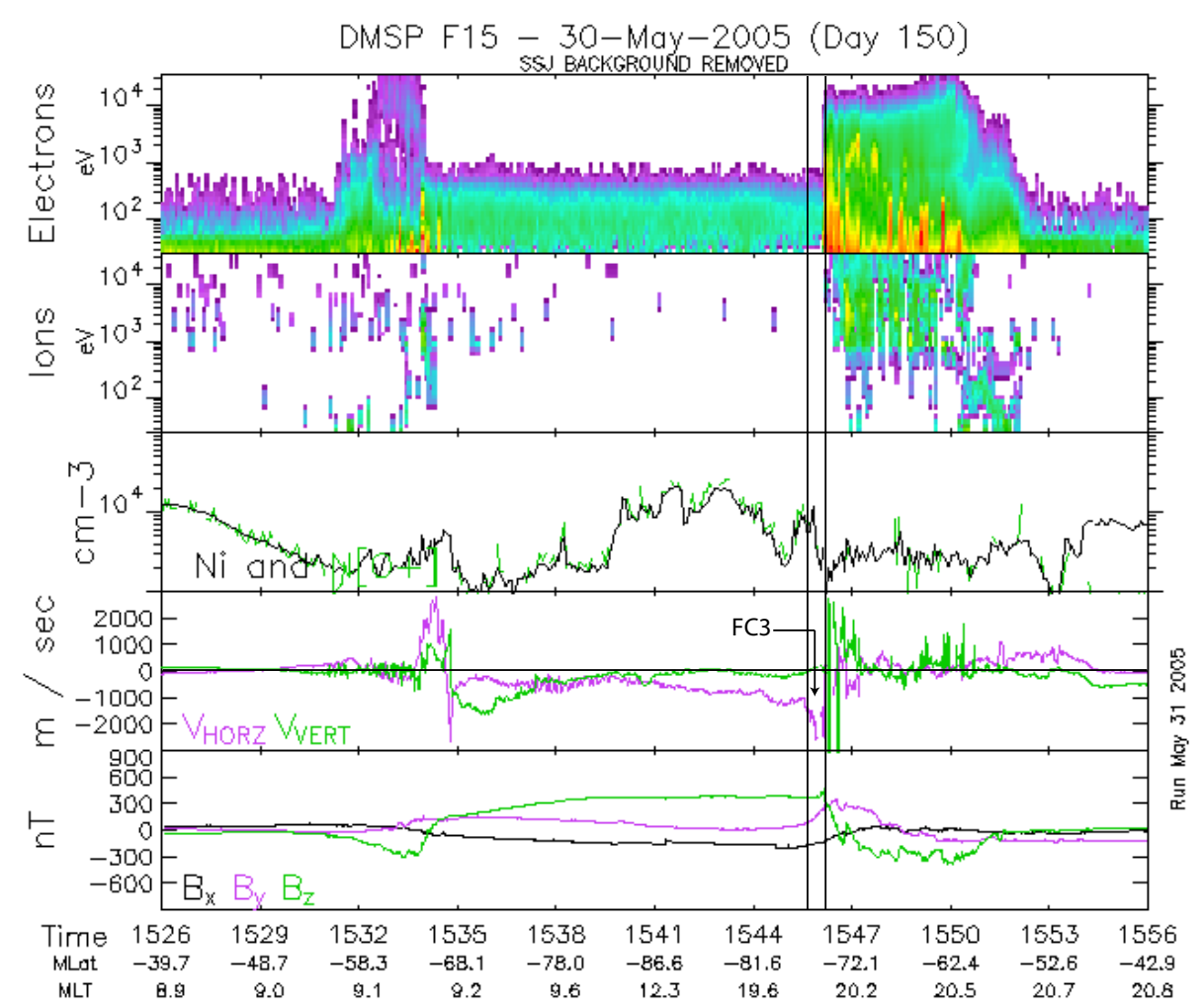

Fig. 8. DMSP F15 data obtained during the Southern Hemisphere pass from pre-noon to pre-midnight in the interval 15:26-15:56 UT on 30 May 2005. Same format as in Fig. 6.

at 14:44 UT) and $74^{\circ}$ MLAT, well into the expansion phase (F13 at 15:14 UT), respectively, and they where close in MLT (see the geometry in Fig. 2). From this observation we infer that the interval between these two crossings is characterised by a significant polar cap contraction, as expected during the substorm expansion phase.

From the above considerations we obtain the following estimates of CPCP average increases occurring during the individual events in the series of PCN-enhancements (substorm expansions) from 3 to $4.5 \mathrm{mV} \mathrm{m}^{-1}$ (with corresponding $L_{\mathrm{PC}}$ decreases) in our case (see the interval from 12:00 UT onwards in Fig. 1): 120-150 kV.

In Fig. 11 we plot $E_{\mathrm{KL}}$ and the Hill-Siscoe cross-polar cap potential $\left(\Phi_{\mathrm{H}-\mathrm{S}}\right)$ for our case. Both expressions are based on interplanetary parameters given in Fig. 1. Quantity $\Phi_{\mathrm{H}-\mathrm{S}}$ depends on $E_{\mathrm{KL}}$, the conductance $\left(\Sigma_{\mathrm{P}}\right)$, and the solar wind dynamic pressure. The curves in the middle and bottom panels of the figure show results for ionospheric conductance values $\Sigma_{\mathrm{P}}=5$ and 10 mhos, respectively. $\Phi_{\mathrm{H}-\mathrm{S}}$ is taken from Eq. (1) in Hairston et al. (2003) and it takes into account the possible CPCP saturation appearing at high levels of interplanetary driving $\left(E_{\mathrm{KL}}>5 \mathrm{mV} \mathrm{m}^{-1}\right)$. In the interval we study in detail (13:00-17:00 UT) $\Phi_{\mathrm{H}-\mathrm{S}}$ increases slightly from 110-115 (150-170) kV, when applying $\Sigma_{\mathrm{P}}=10$ (5) mhos, before the abrupt decrease associated with the northward turning of the
ICME magnetic field affecting Earth from $~ 16: 40$ UT onwards.

The three CPCP values measured by DMSP F13 in the interval 13:00-17:00 UT were 159, 127, and $147 \mathrm{kV}$. These values typically lie between the $\Phi_{\mathrm{H}-\mathrm{S}}\left(\Sigma_{\mathrm{P}}=10 \mathrm{mho}\right)$ and $\Phi_{\mathrm{H}-\mathrm{S}}\left(\Sigma_{\mathrm{P}}=5 \mathrm{mho}\right)$ curves. One exception is the CPCP value derived from the F13 ion drift measurements centred at 16:59 UT, which did not reflect the $E_{\mathrm{KL}}$ drop estimated to occur at 16:40 UT. The convection response to the abrupt $E_{\mathrm{KL}}$ decrease is seen in the PCS (winter) index but not in PCN (summer). Reduced polar cap convection velocities are also seen in the Southern Hemisphere data at 17:47 UT (see the bottom right panel in Fig. 9).

We note that the Hill-Siscoe potential shows smooth and small variations which are closely related to the corresponding smooth and small changes of the interplanetary parameters $\left(E_{\mathrm{KL}}\right) . \Phi_{\mathrm{H}-\mathrm{S}}\left(\Sigma_{\mathrm{P}}=10 \mathrm{mho}\right)$ represents a good estimate of the background inter-substorm level of polar cap convection in the persistent phase of our case.

\section{Discussion}

Contrary to most previous studies of the convection response to magnetospheric substorms, emphasising intervals of isolated substorms (see Introduction), we focus here on the phenomenon of repetitive substorm expansions. In a 


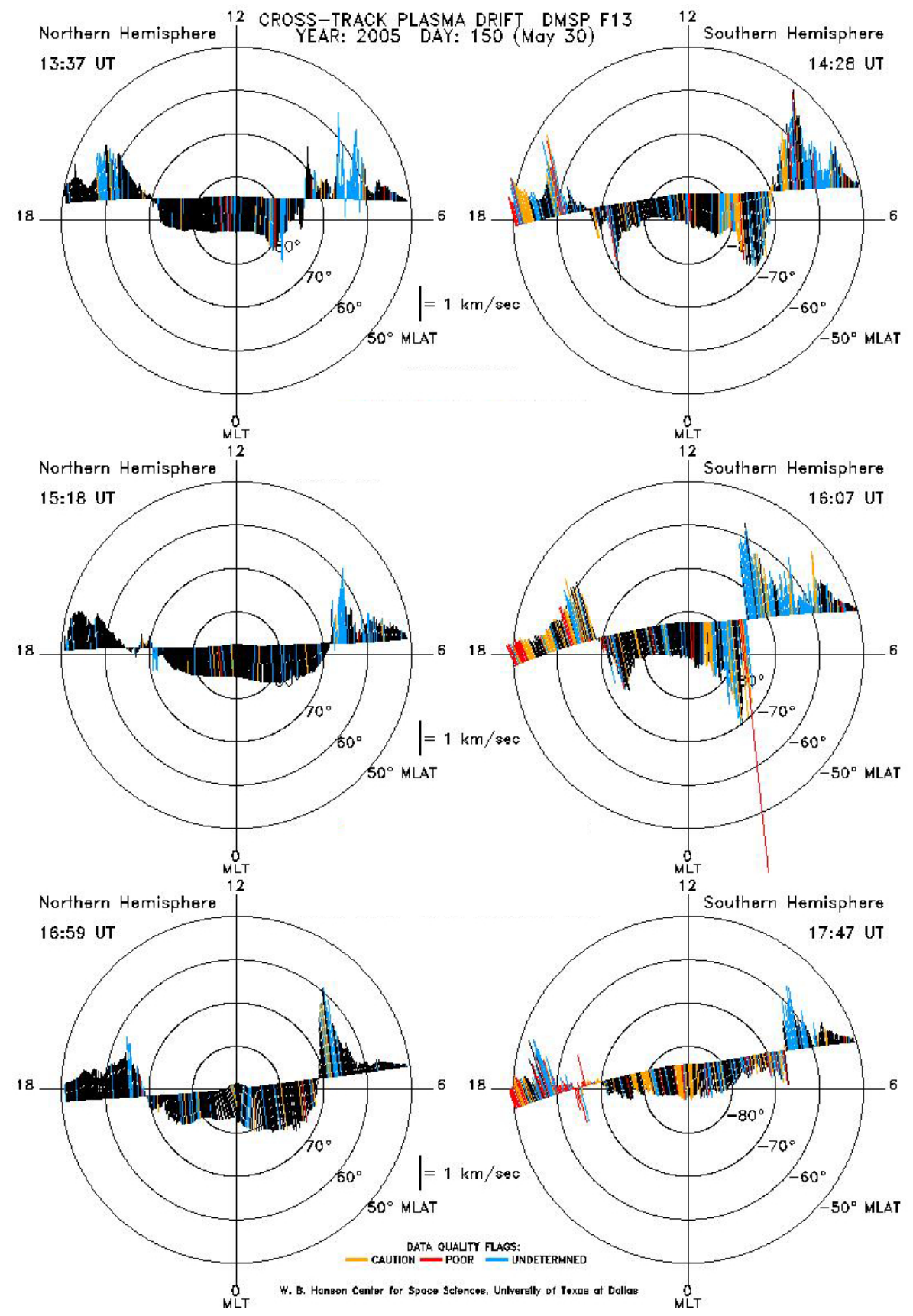

Fig. 9. DMSP F13 cross-track ion drifts on 30 May 2005 obtained during consecutive passes of the polar cap in the Northern (summer; left panels) and in the Southern (winter; right panels) Hemispheres during the interval 13:30-18:00 UT. The centre times of each polar cap crossing are given. The coordinate system is MLAT/MLT.

ground-satellite conjunction study we documented a mode of $50 \mathrm{~min}$ period pulsed polar cap convection (PC-index fluctuations) driven by the repetitive substorm activity characterised by $\sim 15$-min-long, major electrojet intensifications. We apply the $1 \mathrm{~min}$ resolution PC-index as a continuous monitor of the detailed temporal evolution of polar cap convection (Troshichev et al., 2000). This indirect information (equivalent convection) from the central polar cap is com- bined with the more direct, but at lower resolution, ion drift data obtained from satellites in polar orbit. This combination of different datasets is used to estimate the CPCP temporal variability for a selected time interval of the several hours long repetitive substorm activity. Our estimate of a $30 \mathrm{kV}$ CPCP enhancement $(25 \%)$ during the individual substorm expansions in this case study compares well with the MHD simulation results of Gordeev et al. (2011). 


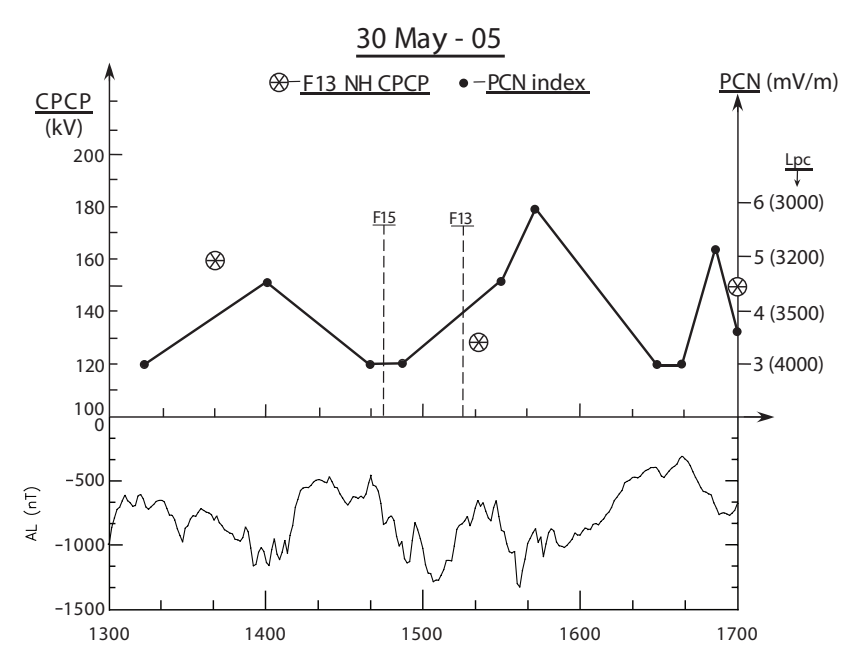

Fig. 10. The top panel shows CPCP estimates during the interval 13:00-17:00 UT on 30 May 2005 as derived from DMSP F13 crosstrack ion drifts (circled crosses at 13:37, 15:18, and 16:59 UT) and the trend of the PCN-index (dots) taken from Fig. 3. The AL-index is shown in the bottom panel. Crossings of the dusk-side polar cap boundary by satellites F15 at 14:44 UT ( $71^{\circ}$ MLAT) and F13 at 15:14 UT $\left(74^{\circ} \mathrm{MLAT}\right)$ are indicated.

This interval was initiated by an abrupt enhancement of $E_{\mathrm{KL}}$ from 4 to $7 \mathrm{mV} \mathrm{m}^{-1}$ associated with the southward turning of the ICME magnetic field recorded by Wind at 05:40UT. The general response to abrupt $E_{\mathrm{KL}^{-}}$ enhancements are divided into two phases, as suggested by Siscoe et al. (2011): (i) an initial transient phase of dayside magnetic flux erosion and the build-up of the dayside R1 current system with associated plasma convection enhancement, and (ii) a long persistent phase characterised by repetitive substorm activity accompanied by convection events. From the PCN trace in our case we may distinguish between three phases: (i) initial transient phase (PCN/day increase), (ii) intermediate phase (PCN/day decreasing from 6 to 3), and (iii) persistent phase with steady PCN/day component $(\mathrm{PCN} /$ day $=3)$ and repetitive $\mathrm{PCN} /$ night enhancements from 12:00 UT onwards.

The case of repetitive substorm activity occurred during a 10-h-long interval of continuously high solar wind forcing associated with the ICME Earth passage on 30 May 2005. The series of PC-index enhancements occurring on time scales of the electrojet intensifications is attributed to the nightside source of polar cap convection. Our separation of the $\mathrm{PC}$ index into a component driven by the dayside convection source (PC/day) and another component driven by the nightside source (PC/night) is consistent with the results of Kullen et al. (2010) on the separation of the dayside and nightside contributions to the $\mathrm{CPCP}, \mathrm{CPCP} /$ day and CPCP/night (see their Fig. 7).

The response of the PC-index (fluctuations) to substorm activity (AL-events) is even larger in the winter (PCS-index)
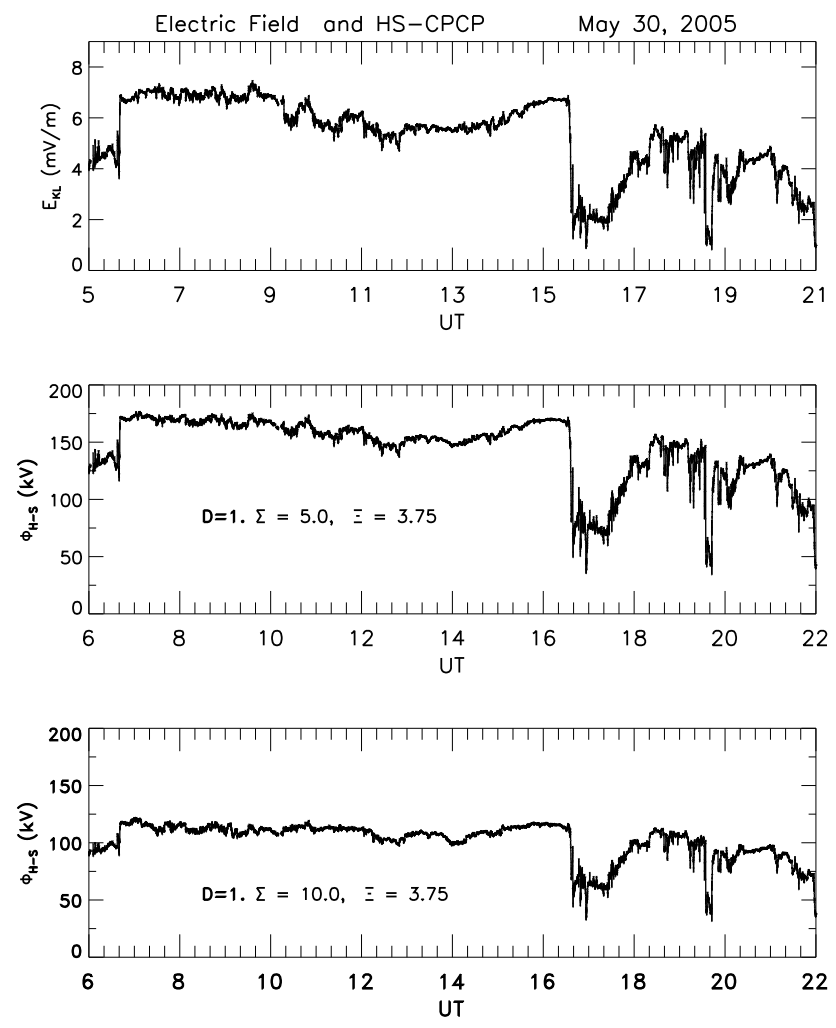

Fig. 11. The geoeffective interplanetary $\boldsymbol{E}$-field $\left(E_{\mathrm{KL}}\right)$ and HillSiscoe CPCPs $\left(\Phi_{\mathrm{H}-\mathrm{S}}\right)$ during the interval 06:00-22:00 UT on 30 May 2005. $\Phi_{\mathrm{H}-\mathrm{S}}$ is taken from Eq. (1) in Hairston et al. (2003). Hill-Siscoe potentials are calculated for the two ionospheric conductance values $\Sigma_{\mathrm{P}}=5 \mathrm{mho}$ (second panel) and 10 mho (bottom).

than in the summer hemisphere, consistent with the results of Janzhura et al. (2007) and Troshichev and Janzhura (2009). Like us, Troshichev and Janzhura (2009) reported a study of the PC-index where they included intervals of repetitive substorm activity appearing when $E_{\mathrm{KL}}$ reached $5-6 \mathrm{mV} \mathrm{m}^{-1}$. We emphasise the role of the nightside source of polar cap convection, as predicted by the expansion-contraction model of polar cap convection (Siscoe and Huang, 1985; Cowley and Lockwood, 1992). The latter perspective is lacking in Troshichev and Janzhura (2009).

The AL-events we study show some characteristics in common with the so-called sawtooth events (SEs) (Henderson et al., 2006), i.e., their quasi-periodicity and occurrence during intervals of continuously moderate-to-strong interplanetary forcing. The $\sim 50 \mathrm{~min}$ average recurrence period observed in our case, is, however, different from the $2-4 \mathrm{~h}$ periods of recurring SEs that has been reported in the literature (see e.g., Henderson et al., 2006, and Huang, 2011). The short recurrence period in our case may be due to the short or absent growth phase as has been pointed out in relation to similar cases documented by Troshichev and Janzhura (2009). According to Huang (2011) substorms may be triggered by moderate solar wind dynamic pressure pulses if the 
magnetotail lobe flux lies at a critical level of $1 \mathrm{GWb}$. We notice the presence of repetitive pressure pulses in our case (see Fig. 1).

We selected the sub-interval 14:40-16:30 UT for a detailed study of polar cap convection during the evolution of the substorm, since (i) this interval is representative for the long interval of repetitive substorm activity, and (ii) there is very good coverage of ground-satellite data in the different substorm phases. This allowed us to document the detailed association between polar cap contraction and convection enhancement during the substorm expansion phase. The amplitude of the fluctuations in the estimated CPCP $(\sim 120$ $180 \mathrm{kV}$ ) we obtained during the slowly increasing IP driving $\left(E_{\mathrm{KL}}=5.5-7 \mathrm{mV} \mathrm{m}^{-1}\right)$ in the interval 13:00-16:30 UT is larger than observed in previous studies that are restricted to lower levels of external forcing $\left(E_{\mathrm{KL}} \leq 3 \mathrm{mV} \mathrm{m}^{-1}\right.$; see Bristow et al., 2004). The estimated $25 \%$ CPCP enhancements in response to individual substorm expansions in our case are not captured by the Hill-Siscoe formula (Hairston et al., 2003) which is based on interplanetary parameters and ionospheric conductivity.

During winter conditions, when large conductivity gradients are present at the polar cap boundary, the condition of enhanced antisunward convection in the night sector of the polar cap is expected to give rise to flow channel FC 3 (see Andalsvik et al., 2011, their Fig. 1). This is exactly what we observed by spacecraft DMSP F15 when it traversed the nightside polar cap boundary in the Southern Hemisphere at 15:46 UT, in the late expansion phase, in our case (see Fig. 8). This observation confirms the previous results of Wang et al. (2010), demonstrating that these events occur in intervals of enhanced $E_{\mathrm{KL}}$ in winter. Furthermore, we postulate that these flows at the nightside polar cap boundary are also enhanced by substorm activity. This is a natural consequence of the two-source nature of polar cap convection. The two sources are dayside (magnetopause) and nightside (magnetotail) reconnection processes. The FC 3 flow channel observation at 15:46 UT occurred at the time of auroral streamer activity as inferred from the magnetograms in Fig. 5. On the association between auroral and magnetic signatures of streamers we refer to Sandholt et al. (2002).

Auroral streamers have been demonstrated to be an ionospheric signature of localised magnetotail magnetic field dipolarizations and bursty bulk flows (BBFs) (Sergeev et al., 2004; Lyons et al., 2012). It is likely that such smaller scale dipolarizations (compared to substorm onset events) also give rise to enhanced $\boldsymbol{E}$-fields in the tail lobe, such as observed by Sauvaud et al. (2012) at substorm onsets. The role of Earthward-propagating dipolarisation front flow bursts within $X=-20$ to $-10 R_{\mathrm{E}}$ as a basic element (substructure) in the substorm process in the magnetotail is emphasized by Lyons et al. (2012). On the association between dipolarization of flux tubes, inward transport of flux from the tail, and the generation of twin-cell flow in the ionosphere we refer to the review paper by Cowley (2000) and the recent simulation results of Yang et al. (2012).

Our study of the substructure of one substorm interval documented the presence of auroral streamer activity, as inferred from the ground magnetograms (series of equatorward-moving X-component deflections), and a polar cap flow channel (F13/F15 ion drift data) in the winter hemisphere. These observations may indicate a relationship between Earthward-moving magnetotail dipolarisation fronts/BBFs (Lyons et al., 2012) and the activation of ionospheric convection channel events along the nightside polar cap boundary (our FC 3; marked in Fig. 2).

\section{Summary}

In a case study, we documented interesting spatial and temporal structure of polar cap convection during a long interval of strong and steady interplanetary driving. This was characterised by a series of substorm expansions - polar cap contractions recurring at $\sim 50 \mathrm{~min}$ intervals. The temporal structure consists of quasi-periodic enhancements of antisunward convection associated with the repetitive substorm expansions. The convection response to these substorms is observed in both the summer and winter hemispheres, but it is larger in the winter hemisphere ( $\triangle \mathrm{PCS} / \mathrm{PCS}>\triangle \mathrm{PCN} / \mathrm{PCN})$. The observed behaviour of polar cap contraction and convection enhancement can be explained by the two-component expansion-contraction model of plasma convection. A combination of ground and satellite observations allowed us to estimate typical (average) CPCP enhancements of $\sim 30 \mathrm{kV}$ (25\%) occurring in the Northern (summer) Hemisphere (PCN-enhancements from 3 to $4.5 \mathrm{mV} \mathrm{m}^{-1}$ ) associated with the individual polar cap contraction events in the series of substorm expansions in the persistent phase of solar windmagnetosphere coupling. The spatial convection structure we emphasize consists of flow channels along the nightside polar cap boundary which is restricted to the winter hemisphere in this case. Plasma flows in these channels are possibly enhanced during the intervals of substorm expansion.

Acknowledgements. We thank the World Data Center in Kyoto, Japan for providing PCN index and O. Troshichev for providing us with PCS data. Access to the DMSP data base was kindly provided by Kevin Martin of Boston College (https://dmsp.isr.bc.edu). Ground magnetograms from the Svalbard IMAGE chain of ground stations were obtained from http://www.geo.fmi.fi/image. We thank Truls Lynne Hansen and Ari Viljanen for operating the IMAGE chain magnetometers. We thank both referees for constructive criticism. Work at University of Oslo is supported by the Norwegian Research Council (NFR). Work at UNH is supported by NASA grant NNX10AQ29G.

Topical Editor R. Nakamura thanks A. Kullen and one anonymous referee for their help in evaluating this paper. 


\section{References}

Andalsvik, Y. L., Sandholt, P. E., and Farrugia, C. J.: Dayside and nightside contributions to cross-polar cap potential variations: the 20 March 2001 ICME case, Ann. Geophys., 29, 2189-2201, doi:10.5194/angeo-29-2189-2011, 2011.

Andalsvik, Y., Sandholt, P. E., and Farrugia, C. J.: Substorms and polar cap convection: the 10 January 2004 interplanetary CME case, Ann. Geophys., 30, 67-80, doi:10.5194/angeo-30-67-2012, 2012.

Bristow, W. A., Greenwald, R. A., Shepherd, S. G., and Hughes, J. M.: On the observed variability of the cross-polar cap potential, J. Geophys. Res., 109, A02203, doi:10.1029/2003JA010206, 2004.

Burlaga, L. F., Sittler, E., Mariani, F., and Schwenn, R.: Magnetic loop behind an interplanetary shock: Voyager, Helios, and IMP-8 observations, J. Geophys. Res., 86, 6673-6684, 1981.

Cowley, S. W. H.: Magnetosphere-ionosphere interactions: A tutorial review, in: Magnetospheric Current Systems, Geophysical Monograph Series, vol. 118, pp. 91-106, AGU (American Geophysical Union), Washington D.C., USA, 2000.

Cowley, S. W. H. and Lockwood, M.: Excitation and decay of solar wind-driven flows in the magnetosphere-ionosphere system, Ann. Geophys., 10, 103-115, 1992.

Crooker, N. U., Lyon, J. G., and Fedder, J. A.: MHD model merging with IMF $B_{\mathrm{y}}$ : Lobe cells, sunward polar cap convection, and overdraped lobes, J. Geophys. Res., 103, 9143-9151, 1998.

Dungey, J. W.: Interplanetary magnetic field and the auroral zones, Phys. Rev. Lett., 6, 47-48, 1961.

Farrugia, C. J., Freeman, M. P., Burlaga, L. F., Lepping, R. P., and Takahashi, K.: The Earth's magnetosphere under continued forcing: Substorm activity during the passage of an interplanetary magnetic cloud, J. Geophys. Res., 98, 7657-7671, 1993.

Feldstein, Y. I., Popov, V. A., Cumnock, J. A., Prigancova, A., Blomberg, L. G., Kozyra, J. U., Tsurutani, B. T., Gromova, L. I., and Levitin, A. E.: Auroral electrojets and boundaries of plasma domains in the magnetosphere during magnetically disturbed intervals, Ann. Geophys., 24, 2243-2276, doi:10.5194/angeo-242243-2006, 2006.

Fox, N. J., Cowley, S. W. H., Davda, V. N., Enno, G., FriisChristensen, E., Greenwald, R. A., Hairston, M. R., Lester, M., Lockwood, M., Lühr, H., Milling, D. K., Murphree, J. S., Pinnock, M., and Reeves, G. D.: A multipoint study of a substorm occurring on 7 December, 1992, and its theoretical implications, Ann. Geophys., 17, 1369-1384, doi:10.1007/s00585-999-13696, 1999.

Gao, Y., Kivelson, M. G., Walker, R. J., and Weygand, J. M.: Long-term variation of driven and unloading effects on polar cap dynamics, J. Geophys. Res., 117, A02203, doi:10.1029/2011JA017149, 2012.

Gordeev, E. I., Sergeev, V., Pulkkinen, T. I., and Palmroth, M.: Contribution of magnetotail reconnection to the cross-polar cap electric potential drop, J. Geophys. Res., 116, A08219, doi:10.1029/2011JA016609, 2011.

Greenwald, R. A., Ruohoniemi, J. M., Baker, K., Bristow, W. A., Sofko, G. J., Villain, J. P., Lester, M., and Slavin, J.: Convective response to a transient increase in dayside reconnection, J. Geophys. Res., 104, 10007-10015, 1999.

Grocott, A., Cowley, S. W. H., Sigwarth, J. B., Watermann, J. F., and Yeoman, T. K.: Excitation of twin-vortex flow in the nightside high-latitude ionosphere during an isolated substorm, Ann. Geophys., 20, 1577-1601, doi:10.5194/angeo-20-1577-2002, 2002.

Grocott, A., Milan, S. E., and Yeoman, T. K.: Superposed epoch analysis of the ionospheric convection evolution during substorms: IMF $B_{\mathrm{y}}$ dependence, J. Geophys. Res., 115, A00I04, doi:10.1029/2010JA015663, 2010.

Hairston, M. R., Heelis, R. A., and Rich, F. J.: Analysis of the ionospheric cross polar cap potential using DMSP data during the National Space Weather Program study period, J. Geophys. Res., 103, 26337-26347, 1998.

Hairston, M. R., Hill, T. W., and Heelis, R. A.: Observed saturation of the ionospheric polar cap potential during the 31 March 2001 storm, Geophys. Res. Lett., 30, 1325, doi:10.1029/2002GL015894, 2003.

Henderson, M. G., Skoug, R., Donovan, E., Thomsen, M. F., Reeves, G. D., Denton, M. H., Singer, H. J., McPherron, R. L., Mende, S., Immel, T. J., Sigwarth, J. B., and Frank, L. A.: Substorms during the 10-11 August 2000 sawtooth event, J. Geophys. Res., 111, A06206, doi:10.1029/2005JA011366, 2006.

Huang, C.-S.: Relation between magnetotail magnetic flux and changes in the solar wind during sawtooth events: Towards resolving the controversy of whether all substorms are externally triggered, J. Geophys. Res., 116, A04202, doi:10.1029/2010JA016371, 2011.

Janzhura, A., Troshichev, O., and Stauning, P.: Unified PC indices: Relation to isolated magnetic substorms, J. Geophys. Res., 112, A09207, doi:10.1029/2006JA012132, 2007.

Kan, J. R. and Lee, L. C.: Energy coupling function and solar windmagnetosphere dynamo, Geophys. Res. Lett., 6, 577-580, 1979.

Kullen, A., Ohtani, S., and Karlsson, T.: Geomagnetic signatures of auroral substorms preceded by pseudobreakups, J. Geophys. Res., 114, A04201, doi:10.1029/2008JA013712, 2009.

Kullen, A., Karlsson, T., Cumnock, J. A., and Sundberg, T.: Occurrence and properties of substorms associated with pseudobreakups, J. Geophys. Res., 115, A12310, doi:10.1029/2010JA015866, 2010.

Lockwood, M., Cowley, S. W. H., and Freeman, M. P.: The excitation of plasma convection in the high-latitude ionosphere, J. Geophys. Res., 95, 7961-7972, 1990.

Lockwood, M., Hairston, M., Finch, I., and Roillard, A.: Transpolar voltage and polar cap flux during the substorm cycle, J. Geophys. Res., 114, A0120, doi:10.1029/2008JA013697, 2009.

Lyons, R. L., Nishimura, Y., Xing, X., Runov, A., Angelopoulos, V., Donovan, E., and Kikuchi, T.: Coupling of dipolarisation front flow bursts to substorm expansion phase phenomena within the magnetosphere, J. Geophys. Res., 117, A02212, doi:10.1029/2011JA017265, 2012.

Muhlbachler, S., Farrugia, C. J., Raeder, J., Biernat, H. K., and Torbert, R.: A statistical investigation of dayside magnetosphere erosion showing saturation of response, J. Geophys. Res., 110, A11207, doi:10.1029/2005JA011177, 2005.

Newell, P. T., Feldstein, Y. I., Y., and Meng, C.-I.: Morphology of nightside precipitation, J. Geophys. Res., 101, 10737-10748, 1996.

Provan, G., Lester, M., Mende, S. B., and Milan, S. E.: Statistical study of high-latitude plasma flow during magnetospheric substorms, Ann. Geophys., 22, 3607-3624, doi:10.5194/angeo-223607-2004, 2004. 
Richardson, I. G. and Cane, H. V., Near-Earth interplanetary coronal mass ejections during solar cycle 23 (1996-2009): Catalog and summary of properties, Solar Phys., 264, 189-237, 2010.

Sandholt, P. E. and Farrugia, C. J.: Poleward moving auroral forms (PMAFs) revisited: responses of aurorae, plasma convection and Birkeland currents in the pre- and postnoon sectors under positive and negative IMF $B_{\mathrm{y}}$ conditions, Ann. Geophys., 25, 16291652, doi:10.5194/angeo-25-1629-2007, 2007.

Sandholt, P. E. and Farrugia, C. J.: Plasma flow channels at the dawn/dusk polar cap boundaries: momentum transfer on old open field lines and the roles of IMF $B_{\mathrm{y}}$ and conductivity gradients, Ann. Geophys., 27, 1527-1554, doi:10.5194/angeo-271527-2009, 2009.

Sandholt, P. E., Farrugia, C. J., Lester, M., Cowley, S. W. H., Milan, S., Denig, W. F., Lybekk, B., Trondsen, E., and Vorobjev, V.: Multistage substorm expansion: Auroral dynamics in relation to plasma sheet particle injection, precipitation, and plasma convection, J. Geophys. Res., 107, 1342, doi:10.1029/2001JA900116, 2002.

Sauvaud, J.-A., Jacquey, C., Oka, M., Palin, L., Fruit, G., Kistler, L. M., Balough, A., Cao, J. B., Reeves, G., Mukai, T., Shinohara, I., and Grigorenko, E.: A study of the near-Earth plasma sheet and lobe driven by multiple substorms: Comparisons with a full particle simulation of reconnection, J. Geophys. Res., 117, AO1221, doi:10.1029/2011JA017033, 2012.

Sergeev, V. A., Liou, K., Newell, P. T., Ohtani, S.-I., Hairston, M. R., and Rich, F.: Auroral streamers: characteristics of associated precipitation,convection and field-aligned currents, Ann. Geophys., 22, 537-548, doi:10.5194/angeo-22-537-2004, 2004.

Sergeev, V., Nishimura, Y., Kubyshkina, M., Nakamura, R., and Singer, H.: Magnetospheric location of the equatorward prebreakup arc, J. Geophys. Res., 117, A01212, doi:10.1029/2011JA017154, 2012.

Shi, Y., Zesta, E., Lyons, L., Boudouridis, A., Ge, Y. S., Ruohoniemi, J. M., and Mende, S.: Two-dimensional ionospheric flow pattern associated with auroral streamers, J. Geophys. Res., 117, A02208, doi:10.1029/2011JA017110, 2012.
Siscoe, G. L. and Huang, T. S.: Polar cap inflation and deflation, J. Geophys. Res., 90, 543-547, 1985.

Siscoe, G. L., Erickson, G. M., Sonnerup, B. U. O., Maynard, N. C., Schoendorf, J. A., Siebert, K. D., Weimer, D. R., White, W. W., and Wilson, G. R.: Hill model of transpolar potential saturation: Comparison with MHD simulations, J. Geophys. Res., 107, 1085, doi:10.1029/2001JA000109, 2002.

Siscoe, G. L., Farrugia, C. J., and Sandholt, P. E.: Comparison between the two basic modes of magnetospheric convection, J. Geophys. Res., 116, A05210, doi:10.1029/2010JA015842, 2011.

Southwood, D. J.: The ionospheric signature of flux transfer events, J. Geophys. Res., 92, 3207-3213, 1987.

Tomita, S., Nosé, M., Iyemori, T., Toh, H., Takeda, M., Matzka, J., Bjornsson, G., Saemundsson, T., Janzhura, A., Troshichev, O., and Schwarz, G.: Magnetic local time dependence of geomagnetic disturbances contributing to the AU and AL indices, Ann. Geophys., 29, 673-678, doi:10.5194/angeo-29-673-2011, 2011.

Troshichev, O. and Janzhura, A.: Relationship between the PC and $\mathrm{AL}$ indices during repetitive bay-like magnetic disturbances in the auroral zone, J. Atmos. Sol. Terr. Phys., 71, 1340-1352, 2009.

Troshichev, O. A., Lukianova, R. Y., Papitashvili, V. O., Rich, F. J., and Rasmussen, O.: Polar cap index (PC) as a proxy for ionospheric electric field in the near-pole region, Geophys. Res. Lett., 27, 23, doi:10.1029/2000GL003756, 2000.

Wang, H., Lühr, H., and Ridley, A. J.: Plasma convection jets near the poleward boundary of the nightside auroral oval and their relation to Pedersen conductivity gradients, Ann. Geophys., 28, 969-976, doi:10.5194/angeo-28-969-2010, 2010.

Yang, J., Toffoletto, F. R., Wolf, R. A., Sazykin, S., Ontiveros, P. A., and Weygand, J. M.: Large-scale current systems and ground magnetic disturbance during deep substorm injections, J. Geophys. Res., 117, A04223, doi:10.1029/2011JA017415, 2012. 